\title{
ONTOLOGÍA JURÍDICA Y TEORÍA QUEER: HACIA (EL FRACASO DE) LA REVUELTA
}

\author{
Daniel J. García-López ${ }^{1}$
}

\section{Resumen}

En el texto reflexionaremos sobre cómo la teoría queer, en el ámbito de los posfeminismos, puede abrir una grieta en el derecho. Se esbozan tres ideas. En primer lugar, se trata de deconstruir la idea de la universalidad (en tiempo y espacio) de categorías como derecho o sexo. En segundo lugar, se plantea la diferencia entre ley y norma para hablar de la imposición de la coherencia narrativa de los cuerpos. En tercer lugar, situando la categoría cuerpo viviente en el centro, se ensaya una ontología jurídica degenerada en la que se ocupen los dispositivos de producción de subjetividad a partir de la herida, el tiempo queer y el derecho a aparecer.

Palabras clave: Cuerpo viviente; derecho a aparecer; dispositivo de producción de subjetividad; teoría queer; tiempo-ahora.

\section{1. $\quad$ Y en el principio fue el Derecho}

Sus columnas impresionan. Las paredes del edificio están marcadas por los siglos y la sangre. Estamos en la Facultad de Derecho de la Universidad de Granada, el último edificio donde la ciudad nazarí vio en vida a aquel que se llamaba, raramente, Federico ${ }^{2}$. Tenemos 18 años, o casi, y asistimos a nuestra primera clase entre nervios: Derecho Romano. También hubiera podido ser Historia del Derecho e, incluso, Teoría del Derecho. Estas tres asignaturas conforman, me atrevería a decir que en la gran mayoría del sistema universitario latino, las asignaturas básicas de la carrera. Y estas tres asignaturas, con más incidencia en la primera, comienzan con un adagio que suena tal que así: ubi societas, ibi ius. El horror al vacío es el miedo más profundo del jurista.

Ubi societas, ibi ius es un mantra que repiten desde el primer día en la Universidad. Donde hay sociedad, hay derecho se ha trasmitido de generación de juristas en generación, sin crítica ni

\footnotetext{
${ }^{1}$ Licenciado y Doctor en Derecho por la Universidad de Almería. Profesor de Filosofía del Derecho en la Universidad de Granada (España). Ha realizado estancias de investigación en España, Alemania e Italia. Centra su trabajo en la historia de la metáfora orgánica en la ciencia jurídica, la gubernamentalidad de sexualidades disidentes (especialmente, transex e intersexualidad) y el pensiero impolitico. Es autor de los libros "Organicismo silente. Rastros de una metáfora en la ciencia jurídica" (Editorial Comares, 2013) y "Sobre el derecho de los hermafroditas" (Editorial Melusina, 2015). $\begin{array}{llllll}\text { Universidad } & \text { de } & - & \text { Espanada }\end{array}$ http://orcid.org/0000-0003-0601-1395.E-mail: danieljgl@ugr.es
}

\footnotetext{
${ }^{2}$ Federico García Lorca, posiblemente el escritor español más importante del siglo XX, fue retenido y torturado en el edificio de la Facultad de Derecho de la Universidad de Granada, en la parte de lo que era el Gobierno Civil, antes de ser asesinado. En el Hall de la Facultad de Derecho hay varias placas que conmemoran a estudiantes ilustres (Blas Infante, Fernando de los Ríos), pero no se dice nada de Lorca, a pesar de que se sabe (casi) con exactitud en qué celda lo retuvieron (en la primera planta, lo que hoy es el Departamento de Derecho Constitucional).
} 


\section{Quaestio Iuris}

vol. 12, nº. 04, Rio de Janeiro, 2019. pp. $513-531$ DOI: $10.12957 /$ rqi.2020.45127

resistencia. Donde hay sociedad, hay derecho es un instrumento de perpetuación ideológica que impide cualquier visión diferente e inmuniza la reproducción del sistema. Se canta, se recita, se repite, se eterniza. Como ha sostenido Juan-Ramón Capella (2006, p. 19), "los juristas suelen identificar así la sociedad humana con la sociedad organizada políticamente. Y trasladan a esta última un atributo que sólo puede predicarse de la primera: la naturalidad de la sociabilidad”. ¿Qué es lo que esto provoca? La imposibilidad de imaginar una sociedad en la que no existan derecho o Estado.

Toda relación debe ser previsible y calculable. Toda relación debe estar mediada por la ley. Este es uno de los postulados de la matriz ideológica moderna: naturaliza los conceptos, contingentes e históricos, como si siempre hubiesen existido, ya sea el derecho, el sujeto, el sexo o la literatura; provocándose la ficción de su necesidad, universalidad o inmutabilidad. Este horror al vacío jurídico es "de la época en que las relaciones mercantiles tienden a sustituir a cualquier otra relación entre los seres humanos. Y expresa el temor a la aparición de cabos sueltos en el tráfico de mercancías" (Capella, 2006, p. 21). Este aforismo funcionaría como una suerte de hybris del punto cero ${ }^{3}$ : un punto de vista que no admite ser un punto de vista que ha sido narrado como único punto de vista válido, creando la ilusión de un conocimiento universal que se enuncia desde un sujeto deshistorizado y descorporalizado. Pero este canto desentona mucho si hacemos un análisis histórico y antropológico. Donde hay sociedad no tiene por qué haber derecho porque el derecho no ha existido siempre ${ }^{4}$.

Pero no se trata solo de una cuestión de tiempo. También importa el espacio. El derecho no existe en todas las sociedades, por más que la matriz ideológica moderna trate de colonizar todos los lugares. El derecho no es ubicuo. Por eso aquí me gustaría lanzar una hipótesis de trabajo: existen sociedades sin derecho (o sin lo que llamamos desde nuestra visión eurocéntrica derecho) que al mismo tiempo no tienen un sistema binario de las corporalidades. Sociedades en Indonesia, en India, en el Caribe, en México, en Panamá, en el Amazonas (Bolin, 2003; Consentino, 2013; FaustoSterling, 2006; Gómez, 2013; Miano, 2003; 2008, 2008; Pérez Castro, 2001; Roscoe, 1998). Como digo son sociedades no binarias -en el sentido que se concibe el binarismo eurocéntrico-, donde entienden que "hombre" y "mujer" son solo dos variedades más, y al mismo tiempo no tienen derecho tal y como lo conocemos.

\footnotetext{
${ }^{3}$ Tomo la idea de Castro-Gómez (2005).

4 Parafraseo "la literatura no ha existido siempre" (Rodríguez, 1974, p. 5). Sobre sociedades sin derecho, Boaventura de Sousa Santos (2009).
} 
En el mundo occidental existe, por tanto, una ficción: todo sistema político tiene que organizarse jurídicamente en torno a un binario (lícito-ilícito, normal-patológico, hombre-mujer, etc.). Con lo cual el régimen político de la heterosexualidad (Rich, 2001) o el binarismo no solo es político sino también jurídico. El derecho inmuniza la violencia del binarismo o de la heterosexualidad. Paradójicamente en sociedades sin derecho el binarismo o la heterosexualidad no constituyen la norma ${ }^{5}$. El régimen político heterosexual y el binarismo no han existido siempre.

Lo que nos señala esta hipótesis es que el derecho se constituye como un sistema de inmunización de un saber experto que clasifica las corporalidades según el grado de cumplimiento con la norma. Pero sin intención de romantizar estos lugares del no-derecho y del no-binarismo, vivimos en un espacio en el que tenemos derecho y este derecho inmuniza -en un sentido médico y jurídico-el binarismo sexual. Esta inmunización se realiza por medio no tanto de leyes como de normas. Es decir, la fuerza del derecho no solo se realiza por medio de leyes, sino principalmente normas que no están solo en códigos, sino en arquitecturas, en manuales de medicina o protocolos médicos, instalaciones, enunciados científicos, en la configuración de un aula, etc., que producen subjetividades, que nos producen. Es decir, el derecho es un dispositivo -en el sentido de Foucault (1985)-, una red heterogénea de relaciones de saber/poder (cárcel, psiquiátrico, escuela, formas arquitectónicas, procedimientos, reglamentos...) que trata de imprimir sobre el cuerpo de cada individuo un conjunto de saberes, de práctica discursivas y no discursivas, de instituciones, para poder gestionarlo, administrarlo, controlarlo, gobernarlo. Por eso el dispositivo, en tanto red, no funciona desde lo represivo capturando individuos, sino desde la producción de sujetos por medio de un conjunto heterogéneo y multiforme de instituciones, normas, reglamentos, formas de comportamiento, técnicos, etc. que, asignando a un sujeto la potestad para garantizar la veracidad del discurso, controlan, orientan, determinan, modelan y aseguran gestos, conductas, cuerpos, etc.

Por eso el derecho no solo son leyes. También encontramos aparatos, instituciones, reglamentos, actores, destinatarios, normas. Si tradicionalmente la teoría del derecho se ha centrado en la relación de soberanía, el dispositivo nos abre la perspectiva de la dominación. Tal como señaló Foucault: “decir que el problema de la soberanía es el problema central del derecho en las sociedades occidentales significa que el discurso y la técnica del derecho tuvieron la función esencial de disolver, dentro del poder, la existencia de la dominación, reducirla o enmascararla para poner de manifiesto, en su lugar, dos cosas: por una parte, los derechos legítimos de la soberanía y, por la otra, la obligación legal de la obediencia" (Foucault, 2003, pp. 31-32). Por eso el dispositivo funcionará por medio de normas que disciplinan al sujeto durante toda su vida (frente a la ley que

\footnotetext{
${ }^{5}$ Lanzo esta idea como hipótesis de un futuro trabajo.
} 
solo se activa por medio de su vulneración). Desde esta perspectiva, el binarismo sexual y la heterosexualidad se constituyen como un código normativo que excluye, incluso con los bisturís de las mutilaciones genitales (García López, 2015) ${ }^{6}$, a las corporalidades que no se ajusten, que no cumplan con la norma.

En este artículo se parte de la imposibilidad de una teoría jurídica queer stricto sensu, dada la incompatibilidad entre la antinormatividad queer y la normatividad del derecho (García López, 2016a y 2016b) ${ }^{7}$. Lo que aquí se pretende es dar un paso en aquella deconstrucción: cómo pensar un derecho -que quizás ya no pueda llamarse así- que garantice medios materiales para que las vidas queer (o cualquier vida) sean vidas dignas de ser vividas y dignas de ser lloradas.

\section{$2 \quad$ ¿Normalizar lo queer o queerizar la norma?}

\subsection{La norma: coherencia narrativa de los cuerpos}

Decíamos que el derecho no solo son leyes. Norma y ley se diferencian: pasaje del orden soberano de la ley (noción jurídica) a la disciplina de la norma (noción médico-naturalista). La ley, a grandes rasgos, se acciona solo ante una infracción a través de su poder represivo (binarismo: legal/ilegal). Pero la ley se conoce y se puede evitar alejándonos de aquello que prohíbe o sanciona. En cambio, la norma actúa durante toda la vida del ser humano (establece gradaciones, es decir, se puede ser más o menos normal) por medio de instituciones (desde la familia o la escuela). En principio, no se puede evitar, pues solo la conocen aquellos que la establecen a partir de un cierto saber (expertos) ${ }^{8}$. Frente a la abstracción, generalidad, publicidad y carácter represivo de la ley, la norma se sitúa en un nivel empírico y en un espacio determinado, definida por su individualización, por su silencio (no publicidad) y por su carácter ya no represivo sino normalizador. Si la ley es

\footnotetext{
${ }^{6}$ Como dato meramente orientativo, entre 2005 y 2014 Alemania mutiló a más de 1000 bebés intersex (Klöppel, 2016). Se trata de un caso de lo que podríamos entender como tortura legalizada. España no se queda atrás: en febrero de 2018, Naciones Unidas reprobó al Estado español por graves violaciones a los derechos de las personas menores de edad intersex. https://brujulaintersexual.org/2018/02/25/crc77-espana-comunicadoprensa-stopigm/

${ }^{7}$ Con queer nos referimos a una posición teórico-práctica posfeminista iniciada en los años 80 y teorizada a partir de los 90 (De Lauretis, 1991) en la que, a partir de la reapropiación del insulto y de la injuria, se producen identidades estratégicas sobre la base de lo extraño, lo raro, lo torcido, lo desviado, lo excéntrico, lo abyecto como una forma de resistencia antinormativa. Sobre la (in)definición de la teoría queer, Ceballos Muñoz (2005, pp. 165-177). Por eso también la palabra teoría junto a queer tiene un carácter paródico y no normativo.

8 “Si la ley aún sometía la vida a un orden que presuponía, la norma remite a una implicación absoluta entre biología y derecho que, mientras establece jurídicamente los límites de la competencia médica, permite al médico definir el umbral de punibilidad de una conducta ilegal mediante la distinción entre criminalidad y anormalidad" (Esposito, 2005, p. 196).
} 
creada por el consenso político, la norma escapa de toda transparencia. La norma ejerce un control total.

Pero ello no quiere decir que nos encontremos ante un lado explícito y visible -el de la ley y la soberanía- y otro oscuro e implícito -el de la norma y la disciplina-. No se trata de una polarización radical. Simplemente el discurso sobre la disciplina es ajeno a la ley, es decir, no pertenece al ámbito de la soberanía. No se remitirá a la regla jurídica sino a la norma natural "y la jurisprudencia de esas disciplinas será el de un saber clínico”. (Foucault, 2003, p. 41).

¿Qué dice la norma? Impone una coherencia narrativa de los cuerpos. Si antes de la Modernidad el soberano hacía morir y dejaba vivir, en la era biopolítica en la que nos encontramos se hace vivir y se deja morir (Foucault, 2009, pp. 141-169). Es por ello que ya no funcione el delito nefando contra natura que condenaba a las personas intersex a morir en la hoguera por haber atacado a Dios y a la creación (García López, 2015), sino que nos encontramos ante un sistema normativo que separa y clasifica los cuerpos en las categorías normal (que es igual a bueno, bello, lícito, sano, moral) y patológico (anormal, malo, feo, ilícito, insano, inmoral). De tal forma que se establece un deber ser de las corporalidades según el cual una persona con cromosomas XY debe poseer pene y testículos con una forma y tamaño, generar testosterona, manifestarse desde la masculinidad y tener relaciones afectivo-sexuales con una persona con cromosomas XX que debe poseer vagina, útero y ovarios con una forma y tamaño, generar estrógenos, manifestarse desde la feminidad y tener relaciones afectivo-sexuales con una persona con cromosomas XY...coherencia narrativa de los cuerpos. Pero si alguien rompe con esta narración, será situado en el otro extremo y habrá de ser corregido, normalizado, disciplinado para que poco a poco traspase la línea divisoria y se sitúe en el lado de la normalidad pero manteniendo el estigma, la cicatriz, que recuerde que en algún momento perteneció al lado erróneo. Se trata ya no de una violencia explícita, que a ojos de todas las personas es visible en tanto rompe con nuestra cotidianeidad, sino de una violencia implícita, silente, sistémica que no percibimos porque se entiende normal, porque nos atraviesa (Žižek, 2009).

Este código normativo de la razón sexual moderna se basa, en fin, en una falacia que el derecho asume: de un ser extrae un deber ser. Esto es, de lo que podemos verificar por los sentidos, por ejemplo, que una mayoría de personas en un recinto calce el número 39, extraer una norma (deber ser): prohibida la entrada al recinto a las personas que no posean un número 39 de pie. De forma similar ocurre con las orientaciones y diversidades corporales, sexuales y de género. Nuestro sistema jurídico ampara, legitima y protege un sistema médico, un saber científico, que dice que las corporalidades, por ejemplo, intersex son corporalidades patológicas, enfermas, anormales. Tenemos un sistema jurídico que se jacta de la palabra "derechos", pero derechos solo de algunos: 
personas cis, heterosexuales, de clase media, blancas, con "capacidad" y mayores de edad. Por decirlo con Jorge Guillén, el resto, la selva. ¿Y qué ocurre con sus derechos? Quedan en suspenso. Suspensión de derechos en las vallas fronterizas con sus concertinas, suspensión de derechos en los Centros de Internamiento para Migrantes, suspensión de derechos en los quirófanos de los hospitales públicos donde las personas menores intersex acaban siendo mutiladas. Hemos entrado en el tiempo de la suspensión de los derechos (García López, 2019).

\subsection{Cuerpo viviente y heridabilidad}

¿Es posible trazar una vida, una subjetividad, sin relación con el derecho? ¿Podemos pensarpracticar una potencia destituyente capaz de sustraerse de la soberanía (Agamben, 2014, pp. 337338). El soberano puede aceptar cualquier tipo de reivindicación identitaria, incluso la del terrorista. Pero lo que no puede bajo ningún pretexto es consentir una singularidad que haga comunidad sin reivindicar una identidad (Agamben, 2001, p. 68). Por eso Agamben señala que la lucha de la política que viene será entre el Estado (basado en el reconocimiento identitario y sobre la legitimación de su propio poder) y el no-Estado (la humanidad, la singularidad cualsea, una comunidad sin esencia, sin identidad) y ya no la lucha por el control del Estado (Agamben, 2001, pp. 67-68). El ser cualsea es la singularidad de un límite, de un resto. Un resto que deviene torcido, degenerado, desviado, extraño, raro. Un resto que produce un desplazamiento de la burla hacia una herramienta de identificación estratégica en el margen. Un resto que se arma en la frontera de aquellas subjetividades que no encajan en el régimen político heterosexual. Un resto como rara avis (García López, 2016a).

Frente a la norma que impone la coherencia narrativa de los cuerpos, desde lo queer se busca otra narración que degenere las categorías hegemónicas y reapropie los conceptos, que desestabilice la matriz heterosexual de la ley (García López, 2016b). Si algo nos enseña la teoría queer es a poner la corporalidad en el centro del tablero. Bodies that Matter. El derecho ha excluido el cuerpo. Desde Gayo, en sus Instituta, el derecho se ocupa de las cosas y las personas. Ni siquiera ha existido una definición jurídica de cuerpo. Sin embargo, lo que media entre la persona y la cosa es el cuerpo viviente (García López, 2018).

¿Qué es el cuerpo viviente? Es una forma-de-vida, en el sentido que da a este concepto Agamben (2014, pp. 263-264), una vida que queda indisolublemente unida a su forma: la herida producida por los dispositivos biopolíticos de normalización que escinden las vidas en vidas dignas e indignas de ser vividas. Por eso la corporalidad viviente está siendo una subjetividad antiesencialista, 
histórica, múltiple, inestable, abierta, sin una identidad fija sino en proceso, estratégica, performativa, herida, queer. Frente a las comunidades que se construyen sobre la base de la preservación de su identidad cerrada (por ejemplo, la nación) que terminan fosilizadas, el cuerpo viviente hace de la identidad supervivencia y viceversa, de la supervivencia identidad. Se trata de ocupar el dispositivo de producción de subjetividad para hacernos cuerpos vivientes desde la materialidad, producirnos como subjetividades antagonistas.

Aquí es importante traer las reflexiones de Butler. En Precarious Life señala que "cada uno de nosotros se constituye políticamente en virtud de la vulnerabilidad social de nuestros cuerpos" (Butler, 2006, p. 46). En Frames of War. When is Life Grievable? profundiza en esta idea de vulnerabilidad, resignificándola junto con la idea de precariedad: “el 'ser' del cuerpo al que se refiere esta ontología es un ser que siempre está entregado a otros: a normas, a organizaciones sociales y políticas que se han desarrollado históricamente con el fin de maximizar la precariedad para unos y de minimizarla para otros” (Butler, 2010, p. 15). Para desarrollar esta idea propone los términos precariedad (precariousness) y precaridad (precarity). El primero hace referencia a la existencia como condición compartida de la vida. La precariedad es lo que nos sitúa en relación, dependientes para sobrevivir, pues "implica vivir socialmente, es decir, el hecho de que nuestra vida está siempre, en cierto sentido, en manos de otro" (Butler, 2010, p. 30). El primero de los actos precarios es el nacimiento, puesto que la supervivencia del ser recién nacido depende de una "red social de manos" (Butler, 2010, p. 31). No hay cuerpos invulnerables. En tanto seres finitos proyectados a la muerte, solo el cuidado nos hace vivir: "no hay vida sin la necesidad de cobijo y alimento, no hay vida sin una dependencia de redes más amplias de sociabilidad y trabajo, no hay vida que trascienda la dañabilidad y la mortalidad" (Butler, 2010, p. 45). La precariedad, en definitiva, es una condición generalizada en la que es necesario construir condiciones que nos hagan vivir una vida vivible, es decir, una vida digna de ser llorada.

Si el primer término es una condición generalizada y compartida que pone en tela de juicio la ontología del individualismo, el segundo, precaridad, es la condición políticamente inducida que produce una desigual exposición de acuerdo a la distribución de las condiciones materiales de la vida. Butler la define como "esa condición políticamente inducida en la que ciertas poblaciones adolecen de falta de redes de apoyo sociales y económicas y están diferencialmente más expuestas a los daños, la violencia y la muerte" (Butler, 2010, p. 46). Es por ello que la precariedad está diferencialmente distribuida. Aquí radica la paradoja de la precaridad: quien sufre la violencia se ve obligado a acudir al mismo Estado contra quien necesita protección, pero es el mismo Estado contra lo que necesitan protegerse (Butler, 2010, p. 47). 
No obstante, "el reconocimiento de la precariedad compartida introduce unos fuertes compromisos normativos de igualdad e invita a una universalización más enérgica de los derechos, que intente abordar las necesidades humanas básicas de alimentación, cobijo y demás condiciones para poder persistir y prosperar" (Butler, 2010, pp. 50-51). La cuestión clave reside en averiguar por qué determinadas vidas soportan mayor precaridad. La solución está en "la alianza centrada en la oposición a la violencia estatal y su capacidad para producir, explotar y distribuir precaridad para su propio beneficio y para la defensa territorial” (Butler, 2010, p. 55).

La forma de gobierno contemporánea se asienta sobre la precariedad, al no ser esta una condición pasajera sino un proceso en el que se producen sujetos y seguridad/inseguridad. Ya no se trata del contrato social basado en el miedo (Hobbes), en el que se obedece al soberano porque a cambio proporciona protección, sino que la gubernamentalidad contemporánea se basa en la inseguridad social, en la destrucción de los sistemas de protección colectiva, en la promesa de la eliminación de la precariedad o en la amenaza con su prolongación. No existe un reparto igualitario de la precariedad, no hay igualdad en la inseguridad ni fin de las desigualdades. La lógica de gobierno neoliberal tan solo plantea "un equilibrio tolerable, tanto como puede soportar la sociedad, entre diferentes normalidades: entre la normalidad de la pobreza, de la precariedad y la normalidad de la riqueza" (Lorey, 2016, pp. 75-76).

No obstante, esta situación "ofrece la oportunidad de inventar a partir de condiciones precarias de vida y de trabajo, formas nuevas y adecuadas de acción política” (Lorey, 2016, p. 24). ¿De qué forma? Haciendo de la vulnerabilidad un punto de partida para otra política no basada en la lógica de la producción y reproducción de inseguridad. Si lo que nos caracteriza como seres vivos es nuestra vulnerabilidad y necesidad del otro para sobrevivir, nuestra heridabilidad, los cuidados deben situarse como eje central. Pero este eje central debe ser sostenible y ello solo es posible mediante la distribución equitativa de los cuidados ${ }^{9}$. Es preciso integrar el placer del otro en nuestro propio placer sin que medie una ley, como se estableciera en el mundo griego a partir de la epimeleia heautou: una serie de prácticas y técnicas de subjetivación que llevó al ser humano al coraje de la verdad.

\footnotetext{
${ }^{9}$ Desde otra perspectiva, Gilligan propuso la ética del cuidado en contraposición a la ética de la justicia (Kholberg). Esta segunda se basa en el individuo abstracto que imagina cómo sería ponerse en la situación del otro. En contra, Gilligan propone una ética del cuidado donde se pasa de lo abstracto a lo concreto, a lo contextual, a la interrelación por medio del cuidado (responsabilidad) hacia el otro. Pasamos del individuo a la comunidad. De ahí que si la ética de la justicia tiene un carácter normativo, centrado en los derechos, la igualdad y el contrato social, la ética del cuidado se centra en las relaciones y responsabilidades. La responsabilidad del cuidado lleva a "attend to voices other than their own and to include in their judgment other points of view". (Gilligan, 1993, p. 16).
} 
Solo por medio del cuidado de sí y de los otros, de una dietética, es posible constituirse como sujeto ético. Y solo como sujeto ético se puede tener el coraje de la verdad, es decir, el momento parresíastico en el que se dice la verdad y toda la verdad, a pesar de las posibles consecuencias negativas de esa enunciación (Foucault, 2005, p. 349). Cuerpo viviente y arte de la existencia.

\subsection{Queer time}

La vida queda indisolublemente unida a su forma, no pueden ser separada, forma-de-vida (Agamben, 2014, p. 264). La herida como la forma en la que queda indisolublemente unida la vida. La herida como verdad, como decir veraz, como parresía. He aquí la posibilidad de entender la corporalidad cuya singularidad radica en el uso del cuerpo, escapando a la producción, pues no produce nada sino su propio uso. Si la política ha sido pensada a través de la división, de la exclusión y de la inclusión, separando la vida de sí misma y clasificándola en vida humana, vida animal y vida vegetal, quizás sea necesario pensar una política de la forma-de-vida, esto es, de la vida indivisible e inseparable de su forma.

Heridas y cicatrices de las corporalidades vivientes, producidas por los dispositivos biopolíticos, que escinden las vidas en dos: las vidas dignas de ser vividas y las vidas desnudas. Las primeras tendrán los ropajes de la ciudadanía, de la propiedad privada ciudadanía. Las segundas, en cambio, desnudas ante la intemperie, ante la tempestad, fungibles. Por eso, como se señala desde Tiqqun (2008, p. 16), "la guerra civil es el libre juego de las formas-de-vida, el principio de su coexistencia".

La revuelta comienza en y desde las corporalidades. El punto de partida se halla en la necesidad y en la mortalidad de las corporalidades vivientes presentadas en sus heridas. Y su tiempo es el ahora. Ese es el tiempo de la decisión, del tomar partido, del implicarse que es un co-implicarse frente al tiempo que huye, que no busca la transformación, que la evita (el tiempo de lo dejo pasar o al final las cosas cambiarán). En palabras del Comité Invisible (2017, p. 18), “el desastre actual es como la acumulación monstruosa de todos los aplazamientos del pasado, a los cuales se añaden en un desmoronamiento permanente los de cada día y los de cada instante. Pero la vida se juega siempre ahora, y ahora, y ahora".

La corporalidad como palimpsesto de heridas que se yuxtaponen unas sobre otras, heridas palimpsésticas que van escribiendo y reescribiendo (en) el cuerpo. A pesar de cuerpos olvidados, cuerpos exiliados, cuerpos desaparecidos, cuerpos fugados, cuerpos fungibles. Y son estos cuerpos, precisamente, los que signan una época, como el siglo XXI que comenzó el 20 de julio de 2001 bajo las ruedas de un Land Rover Defender en piazza Alimonda. Porque sus heridas hablan y al 
decir tocan y trastocan. Porque proponen otra forma de decir, una otra manera de decir frente a la historia que nos han contado. El decir veraz de la herida es otro decir, otro lenguaje, otra lengua(je) como una carta en la que solo podamos decir (lengua)je suis un autre porque solo por medio de la otredad, del cuidado de la otredad, puedo cuidarme. Solo a partir de que otras heridas hablen, puede venir el silencio. Proponer, por tanto, otro decir con el solo acontecer de la herida. Esta es la potencia de las corporalidades vivientes en la revuelta.

En este palimpsesto que es la revuelta de las corporalidades vivientes, la herida constituye el tiempo. ¿Cómo medir el tiempo de la herida? La historia nos ha proporcionado instrumentos para medir el tiempo: desde el reloj solar hasta el de cualquier celular. También lo hemos contado: noche y día, fases lunares, estaciones. Pero esto no nos sirve a la revuelta. El tiempo de la herida, de la corporalidad herida en la revuelta, es esa otra lengua de la que antes se habló.

La corporalidad como tiempo. La herida como tiempo contra las concepciones lineal (un tiempo que se extiende desde un punto de origen a uno de llegada) y cíclica (su imagen, la rueda, el ciclo de las estaciones, las fases lunares), esto es, lo que se podría llamar crononormatividad. Frente a este tipo de tiempo, en la última década está siendo pensada desde la teoría queer otra forma de experimentarlo (Dinshaw, 2007, pp. 177-195) (Freccero, 2011, pp. 17-26) (Freeman, 2010) muy cercana, pienso aquí, a la idea esbozada por Benjamin del jetztzeit, el tiempo-ahora como tiempo detenido ${ }^{10}$. Se trata de un conjunto de prácticas, experiencias y sensaciones que escapan al modo hegemónico de entender el tiempo, de organizarlo, de valorarlo, lo que supone también entender de otra forma las corporalidades, desde una visión emancipadora.

La temporalidad queer ${ }^{11}$, como temporalidad vivida y experimentada, se muestra disidente ante el tiempo normativo que entiende la vida en una línea recta que va de la infancia sin normas a la madurez ordenada por medio del matrimonio y la reproducción (y la familia heteronormativa) como aparatos disciplinarios (Halberstam, 2005 y 2018). El tiempo queer es un tiempo por fuera del reloj. $\mathrm{Y}$ ello desde la interrupción que provocan unas identidades, como estrategias, como singularidades cualsea, contra el esencialismo, la noción de progreso o la teleología propia de identidades cerradas, monolíticas y unidireccionales. En Gender Trouble de Butler ya encontramos un esbozo de esto.

\footnotetext{
10 “'Los escasos cincuenta mil años del homo sapiens', escribe un biólogo moderno, 'representan en su relación con la historia de la vida orgánica en la tierra algo así como dos segundos al final de un día de veinticuatro horas. La historia de la humanidad civilizada llenaría pues, en esta escala, solo un quinto del último segundo de la última hora'. Así, el tiempo-ahora, que en cuanto modelo del mesiánico resume toda la historia de la humanidad en una gigantesca abreviatura, viene a coincidir exactamente con la figura que la historia de la humanidad compone en el universo en su conjunto" (Benjamin, 2008, p. 317).

${ }^{11}$ Hay dos visiones de la temporalidad queer, a saber: a) subjetividades queer viven tiempos queer alejándose de la crononormatividad heterosexual; b) el tiempo puede volverse queer (Dinshaw, 2012) (Halberstam, 2005).
} 
Partiendo de la idea de que la performatividad no es un acto fundador u origen, "no es un acto único, sino una repetición y un ritual que consigue su efecto a través de su naturalización en el contexto de un cuerpo, entendido, hasta cierto punto, como una duración temporal sostenida culturalmente" (Butler, 2007, p. 17), Butler señala:

"El género no debe considerarse una identidad estable o un sitio donde se funde la capacidad de acción y de donde surjan distintos actos, sino más bien como una identidad débilmente formada en el tiempo, instaurada en un espacio exterior mediante una reiteración de actos. El efecto del género se crea por medio de la estilización del cuerpo y, por consiguiente, debe entenderse como la manera mundana en que los diferentes tipos de gestos, movimientos y estilos corporales crean la ilusión de un yo con género constante. Este planteamiento aleja la concepción de género de un modelo sustancial de identidad y la sitúa en un ámbito que existe una concepción del género como temporalidad social constituida". (2007, Butler, 273-274)

Al entender la performatividad no como origen, sino como reiteración sostenida en el tiempo, se desvanecen las ideas de antes y después. Además, la idea de iteración trae tanto el pasado como el futuro al presente, pues las repeticiones subversivas tienen la capacidad de provocar grietas en las normas de género. De ahí que la heteronormatividad también actúe sobre el tiempo, lo que antes se ha señalado como crononormatividad. Esta consiste en una serie de técnicas (calendarios, agendas, relojes, etc.) que, al inculcar ritmos ocultos, naturalizan experiencias temporales para aquellos sujetos que privilegia (Freeman, 2010, p. 3). Por tanto, vincula normas sexo-genéricas con regulaciones temporales. De lo que se trata es de organizar los cuerpos, sus ritmos, sus tiempos, de la forma más productiva para el sistema económico. Lo que Dana Luciano (2007), siguiendo a Foucault, llamó cronobiopolítica. Una pluralidad de tiempos que conviven simultáneamente: el tiempo de la acumulación del desarrollo (lineal) y el tiempo cíclico de las tareas domésticas. Esta yuxtaposición de tiempos normaliza los cuerpos para adaptarlos al aparato de producción capitalista (he ahí su función biopolítica), haciéndolos pasar por naturales ${ }^{12}$. Es más: el tiempo lineal de producción necesita del tiempo cíclico doméstico (el tiempo del amor, de la seguridad, de la maternidad, de la cena en familia, de la herencia, del fin de semana) (Freeman, 2010, p. 39). Es así

\footnotetext{
${ }^{12}$ Un ejemplo lo tenemos en ese lugar común que tanto la medicina como la sociedad suele expresar: hay que dormir 8 horas. Lo que se presenta como una necesidad natural no es más que el resultado de la lucha obrera conseguido en un determinado momento histórico. "Manipulations of time also convert historically specific regimes of asymmetrical power into seemingly ordinary bodily tempos and routines. Consider, for example, how nineteenth-century workers in the United States and Europe claimed the eighthour workday as part of a triad that included eight hours of sleep and eight hours of leisure. Yet we now understand the need for eight hours of sleep as a demand coming from our body rather than as a form of resistance to wage work" (Freeman, 2007, p. 160).
} 
que pasamos de un modelo de producción basado en el tiempo cíclico de las estaciones, al tiempo biopolítico de la industria.

La temporalidad queer interrumpe la crononormatividad/cronobiopolítica al mostrar la artificialidad de lo que se presenta como natural, esencial, del mismo modo que, desde sus inicios, la teoría queer ha puesto en duda la naturalidad (ahistoricidad, inmutabilidad, etc.) de las categorías sexo-genéricas. El esencialismo temporal es tan artificial como el binarismo sexual y ambos muestran su violencia: si el binarismo, por ejemplo, condena a las personas intersex a la mutilación, el esencialismo temporal ordena la vida de una forma entendida como la única forma válida, de tal manera que presenta una progresión temporal necesaria, privilegiando unas vidas frente a otras, presentándolo como natural y ocultando los elementos políticos: ¿para cuándo los hijos?; ¿estaréis pensando ya en la boda, no?, se te va a pasar el arroz. Frente a este esencialismo, la temporalidad queer destruye el futurismo reproductivo (Edelman, 2014) o el straight time (Muñoz, 2009) desde los parámetros de la monstruosidad ${ }^{13}$. Si la idea de progreso (y éxito) está asociada a la reproducción heterosexual, su opuesto, el retroceso (y el fracaso), viene asignado a aquellas subjetividades atrasadas $^{14}$ que, además, se encuentran dislocadas de cualquier momento histórico (Freeman, 2007, p. 162).

La temporalidad queer se ubica en el cuerpo, en la herida, como el insulto, como la herida del y por el lenguaje. Frente al tiempo heteronormativo del reloj, del progreso capitalista, el tiempo de la herida es el tiempo de la vida. Con el reloj solo se puede ver la hora (o preguntar por ella), con la herida el tiempo se siente, duele, cicatriza, sangra, se infecta, se lame, se reabre. La herida deviene un archivo somático. Si en los archivos hay leyes (como la 16/1985 del Patrimonio histórico español) que limitan e impiden su acceso para proteger la identidad y la honorabilidad de la persona que, por ejemplo, mandó fusilar a otra durante la dictadura franquista ${ }^{15}$, pareciera que la matriz heterosexual ha dictado una ley que impide acudir al archivo somático del cuerpo para abrir los legajos de las heridas que explican nuestra historia. El tiempo-ahora queer es el tiempo de(l derecho a) aparecer.

\subsection{La herida como fuente del derecho a aparecer}

\footnotetext{
${ }^{13}$ Las posiciones de Edelman y Muñoz (o Halberstam) mantienen una diferencia radical: el primero parte de una concepción negativa donde la figura de el niño debe ser eliminada; el segundo, en cambio, plantea una utopía a partir de esa figura.

${ }^{14}$ Un breve repaso a la historia de la criminología nos enseña cómo han sido clasificados como retrasadas e inferiores personas homosexuales, pobres, diverso-funcionales, etc.

${ }^{15}$ Sobre la fuerza normativa de los archivos, los límites a su interpretación y sobre quién autoriza, véase Derrida (1997).
} 
En tanto los cuerpos comparten su finitud, su herida, la cuestión radica en "cuáles son las vidas que se ven interrumpidas con más facilidad" (Butler, 2017, p. 53). De ahí que la justicia no pueda realizarse sin el cuidado de las vidas precarias. Aquí es interesante traer las reflexiones de Butler sobre las acciones corporeizadas que se reúnen en el espacio público, ya sea material o virtual: "por una parte, las protestas se expresan por medio de reuniones, asambleas, huelgas, vigilias, así como en la ocupación de espacios públicos; y por la otra, estos cuerpos son el objeto de muchas de las manifestaciones que tienen en la precariedad su impulso fundamental" (Butler, 2017, p. 17).

Los cuerpos situados en su común vulnerabilidad reclaman su derecho a aparecer en público, a mostrar sus heridas y cicatrices, a exponerse. He ahí su arte de la existencia. Y aunque su presencia pueda no perdurar en el tiempo, su potencia se encuentra en que pueden surgir en cualquier momento (tiempo-ahora). Esto diferencia claramente al sujeto abstracto moderno, base del sistema jurídico y del principio de igualdad formal, de los cuerpos vivientes, de las corporalidades aliadas en y desde la vulnerabilidad, ya no abstracta sino presente en las condiciones materiales que hacen de la vida vivible. Por eso no se trata de alianzas identitarias tendentes a crear comunidades excluyentes: "la precariedad es una categoría que engloba a mujeres, queers y personas transgénero, a los pobres, los discapacitados y los apátridas, pero también a las minorías religiosas y raciales; es pues una condición social y económica, pero no una identidad” (Butler, 2017, p. 63). Para esta comunidad de cuidados de las corporalidades vivientes es imprescindible la hospitalidad de quien viene ahora de forma repentina ${ }^{16}$. Y no hay más que juntarse para comenzar la revuelta: parafraseando a Spinoza, "nadie sabría decir lo que puede un encuentro" (Comité Invisible, 2015, p. 46).

\section{Conclusión ante (el fracaso de) la revuelta}

Berlín, 15 de enero 1919. Rosa Luxemburgo es asesinada, su cuerpo arrojado al Landwehrkanal. Karl Liebknecht es asesinado, su cuerpo es arrojado a una fosa común. ¿El asesino? Friedrich Ebert, líder del partido socialdemócrata alemán, y sus Freikorps. ¿La razón? Spartakusaufstand.

Washington D.C., 11 de octubre de 1992. Pequeños cofres, bolsas y urnas cantan sus nombres asesinados, sus cuerpos en cenizas arrojados al jardín de la White House. ¿El asesino? El vih y el abandono deliberado de Ronald Reagan y George H.W. Bush, presidentes de los Estados Unidos de América. ¿La razón? Bury me furiously.

\footnotetext{
${ }^{16}$ Tomo la idea de hospitalidad según Lévinas y Derrida y contra el simple derecho de visita (Kant).
} 


\section{Quaestio Iuris}

vol. 12, nº. 04, Rio de Janeiro, 2019. pp. $513-531$ DOI: $10.12957 /$ rqi.2020.45127

¿Qué une a spartakistas y Ashes Action de Act Up? La revuelta. La exposición de los cuerpos en la revuelta que aúnan tiempo de la subversión y tiempo de la memoria. Si la revolución consiste en una estrategia a largo plazo en una visión teleológica de la historia, la revuelta supone un estallido insurreccional que puede aparecer en cualquier momento y por eso suspende el tiempo histórico. Ambas, en Berlín y Washington, fracasaron y el dispositivo normalizador realizó sus funciones de formateo y reconstrucción del tiempo normal, straight time ${ }^{17}$. Pero en la revuelta dejamos de estar solos:

"Puede amarse una ciudad, pueden reconocerse sus casas y sus calles en los recuerdos más remotos y secretos; pero solo a la hora de la revuelta la ciudad se siente verdaderamente como la propia ciudad: propia, por ser del yo y al mismo tiempo de los "otros"; propia, por ser el campo de una batalla elegida y que la comunidad ha elegido; propia, por ser el espacio circunscripto en el cual el tiempo histórico está suspendido y en el cual cada acto vale por sí solo, en sus consecuencias absolutamente inmediatas. Nos apropiamos de una ciudad huyendo o avanzando en la alternancia de los ataques, mucho más que jugando, de niños, en sus calles, o paseando luego por los mismos lugares con una muchacha. A la hora de la revuelta, dejamos de estar solos en la ciudad". (Jesi, 2014, p. 72)

Si la estrategia revolucionaria piensa en el largo plazo del mañana, la revuelta lo hace en el larguísimo plazo del pasado-mañana que se retrotrae, incluso, hacia el pasado. Por eso la revuelta es inactual, es impotencia, es pura potencia-de-no. Potencia de vivir sustraída de toda obra. Por decirlo con Agamben, "el ser [cualsea] que puede no ser, que puede la propia impotencia" (Agamben, 2001, p. 33). Si la política tal como se conoce desde Aristóteles ha venido siendo obra, acto (Agamben, 2008, p. 381), es tiempo de la inoperosidad (Agamben, 2001, p. 92), de la desobra, de la pura potencia acontecida en la multitud (Agamben, 2008, p. 387). La vida desnuda, la corporalidad viviente, deviene forma-de-vida que escapa de la lógica soberana, de la lógica de la ley (Agamben, 2014, p. 264).

Hablar de un fracaso de la revuelta o una fracasada teoría queer del derecho es salir de la lógica heterocapitalista del éxito. Como señala Halberstam, "fracasar, perder, olvidar, desmontar, deshacer, no llegar a ser, no saber, puede en realidad ofrecernos formas más creativas, más cooperativas, más sorprendentes, de estar en el mundo" (Halberstam, 2018, p. 14). Hacer una lectura queer del derecho nos pone ante la situación de, parafraseado a Halberstam, devenir matorral "de

\footnotetext{
${ }^{17}$ Furio Jesi definía el tiempo normal como: "no solo un concepto burgués, sino el fruto de una manipulación burguesa del tiempo. Este le garantiza a la sociedad burguesa un transcurrir tranquilo" (2014, p. 80). Podemos vincular esta misma definición con el straight time.
} 
ese conocimiento oprimido que brota como malas hierbas en medio de las formas disciplinarias del conocimiento, siempre amenazando con arruinar el cultivo y con podar el intelecto con la vida de esas plantas locas" (Halberstam, 2018, p. 21). El fracaso ama la compañía (Halberstam, 2018, p. 131) porque acoge la herencia de quienes perdieron antes, la tradición de los oprimidos, "de la imagen fiel de los ancestros que habían sido esclavizados, y no del ideal de los liberados descendientes" (Benjamin, 2008, p. 314). Quizás solo desde estas líneas de la memoria sea posible borrar la línea abisa $1^{18}$ y trazar una democracia somatopolitica.

\title{
LEGAL ONTOLOGY AND QUEER THEORY: TOWARD (THE FAILURE OF) THE REVOLT
}

\begin{abstract}
In the paper we will reflect on how queer theory (in the post-feminisms context) can open a crack in the law. Three ideas are outlined. Firstly, it is a question of deconstructing the idea of universality (in time and space) of categories such as law or sex. Secondly, the difference between law and norm is raised in order to speak of the imposition of the narrative coherence of bodies. Thirdly, by placing the living body category in the center, a degenerate legal ontology is rehearsed in which the device for the production of subjectivity are occupied from the wound, the queer time and the right to appear
\end{abstract}

Keywords: Living body; right to appear; subjectivity production device; now-time; queer theory.

\section{Referencias bibliográficas}

AGAMBEN, Giorgio. La comunità che viene. Tornino: Bollati Boringhieri, 2001.

AGAMBEN, Giorgio. La potencia del pensamiento. Barcelona: Anagrama, 2008.

\footnotetext{
${ }^{18}$ Con línea abisal me refiero al concepto de Boaventura de Sousa Santos (2008)
} 
AGAMBEN, Giorgio. L’uso dei corpi. Homo sacer 4.2. Vicenza: Neri Pozza, 2014.

BENJAMIN, Walter. "Sobre el concepto de historia". Obras, L. I, vol. 2. Madrid: Abada, 2008.

BOLIN, ANNE. "La transversalidad de género. Contexto cultural y práctica de género". Nieto, José Antonio (Ed.). Antropología de la sexualidad y diversidad cultural. Madrid: Talasa, 2003, pp. 231-256.

BUTLER, JUDITH. Vida precaria. El poder del duelo y la violencia. Buenos Aires: Paidós, 2006.

BUTLER, JUDITH. El género en disputa. El feminismo y la subversión de la identidad. Barcelona: Paidós, 2007.

BUTLER, JUDITH. Marcos de guerra. Las vidas lloradas. Barcelona: Paidós, 2010.

BUTLER, JUDITH. Cuerpos aliados y lucha política. Hacia una teoría performativa de la asamblea. Barcelona: Paidós, 2017.

CAPELLA, JUAN-RAMÓN. Fruta prohibida. Una aproximación histórico-teorética al estudio del derecho y del estado. Madrid: Trotta, 2006.

CASTRO-GÓMEZ, SANTIAGO. La hybris del punto cero. Ciencia, raza e ilustración en la Nueva Granada (1750-1816). Bogotá: Pontificia Universidad Javeriana, 2005.

CEBAllos MUÑOZ, Alfonso. "Teoría rarita”. En Córdoba, D., Sáez, J. y Vidarte, P. (Eds.). Teoría queer. Políticas bolleras, maricas, trans, mestizas, 2. ${ }^{\circ}$ ed., Madrid: Ed. Egales, 2005, pp. $165-177$.

COMITÉ INVISIBLE. A nuestros amigos. Logroño: Pepitas de Calabaza, 2015.

COMITÉ INVISIBLE. Ahora. Logroño: Pepitas de Calabaza, 2017.

COSENTINO, Chiara. "La irreducible originalidad del tercer género el caso zapoteco". Gómez, Águeda (Ed.). Nuevas miradas sobre el género, la sexualidad y la etnicidad. Andavira, 2013, pp. $39-72$.

DE LAURETIS, Teresa. "Queer Theory: Lesbian and Gay Sexualities". En Differences: A Journal of Feminist Cultural Studies, n. ${ }^{\circ 3}$, 1991, pp. III-XVIII.

DERRIDA, Jacques. Mal de archivo. Una impresión freudiana. Madrid: Trotta, 1997. 
DINSHAW, Carolyn. "Theorizing queer temporalities". GLQ: A Journal of Lesbian and Gay Studies, 13, 2-3, 2007, pp. 177-195.

DINSHAW, Carolyn. How Soon is Now? Medieval Texts, Amateur Readers, and the Queerness of Time. Durham: Duke University Press, 2012.

EDELMAN, Lee. No future. Queer Time and the Death Drive. Duke University Press, 2004.

ESPOSITO, Roberto. Immunitas. Protección y negación de la vida. Buenos Aires: Amorrortu, 2005.

FAUSTO-STERLING, Anne. Cuerpos sexuados. La política de género y la construcción de la sexualidad. Barcelona: Melusina, 2006.

FOUCAULT, Michel. “El juego de Michel Foucault”. Saber y verdad. Madrid: La Piqueta, 1985.

FOUCAULT, Michel. Hay que defender la sociedad. Curso en el Collège de France (19751976). Madrid: Akal, 2003.

FOUCAULT, Michel. La hermenéutica del sujeto. Curso en el Collège de France (1982). Madrid: Akal, 2005.

FRECCERO, Carla. "Queer Times". Halley, Janet y Parker, Andrew (Eds.). After Sex? On Writing since Queer Theory. London: Duke University Press, 2011, pp. 17-26.

FREEMAN, Elizabeth. "Introduction". GLQ: A Journal of Lesbian and Gay Studies, Vol. 13, n²-3, 2007, pp. 159-176.

FREEMAN, Elizabeth. Time Binds. Queer Temporalities, Queer Histories. London: Duke University Press, 2010.

GARCÍA LÓPEZ, Daniel J. Sobre el derecho de los hermafroditas. Madrid: Melusina, 2015.

GARCÍA LÓPEZ, Daniel J. Rara avis. Una teoría queerimpolítica. Madrid: Melusina, 2016a.

GARCÍA LÓPEZ, Daniel J. “¿Teoría jurídica queer? Materiales para una lectura queer del derecho". Anuario de Filosofía del Derecho, 32, 2016b, pp. 323-348.

GARCÍA LÓPEZ, Daniel J. "Has de tener un cuerpo que mostrar: el grado cero de los derechos humanos". Isegoría, 59, 2018b, pp. 663-682. 
GARCÍA LÓPEZ, Daniel J. Bioestado de excepción. Suspensión del derecho e insurgencia de las corporalidades vivientes. Puerto Rico: Ed. Educación Emergente, 2019.

GILLIGAN, Carol. In a Different Voice. Psychological Theory and Women's Development. Harvard University Press, 1993.

GÓMEZ, Águeda. “Tercer género y etnicidad en América Latina”. Valcuende, José María (Ed.). Diversidad sexual en Iberoamérica. Sevilla: Aconcagua, 2013, pp. 27-49.

HALBERSTAM, Jack. In a Queer Time and Place. Transgender Bodies, Subcultural Lives. New York University Press, 2005.

HALBERSTAM, Jack. El arte queer del fracaso. Madrid: Ed. Egales, 2018.

JESI, Furio. Spartakus. Simbología de la revuelta. Buenos Aires: Ed. Adriana Hidalgo, 2014.

KLÖPPEL, Ulrike. "Zur Aktualität kosmetischer Operationen „uneindeutiger“ Genitalien im Kindesalter”. Bulletin-Texte / Zentrum für transdisziplinäre Geschlechterstudien, 2016.

LOREY, Isabell. Estado de inseguridad. Gobernar la precariedad. Madrid: Traficantes de Sueños, 2016.

LUCIANO, Dana. Arranging Grief. Sacred Time and the Body in Nineteenth-Century America. New York University Press, 2007.

MIANO, Marinella. Hombre, mujer y muxe en el Istmo de Tehuantepec. México: Plaza y Valdés, 2003.

MUÑOZ, José Esteban. Cruising Utopia. The Then and There of Queer Futurity. New York University Press, 2009.

NIETO, José Antonio. Transexualidad, intersexualidad y dualidad de género. Barcelona: Bellaterra, 2008.

PÉREZ CASTRO, Juan Carlos. "Los reneke o nawiki”. Cuicuilco. Homosexualidad, género y cultura en México, Vol 8, n²3, 2001, pp. 33-52.

RODRÍGUEZ, Juan Carlos. Teoría e historia de la producción ideológica. Las primeras literaturas burguesas. Madrid: Ed. Akal, 1974. 
ROSCOE, Will. Changins ones: third and fourth genders in Native North América. New York:

St. Martin's Press, 1998.

RICH, Adrienne. "Heterosexualidad obligatoria y existencia lesbiana". Sangre, pan y poesía, Icaria, 2001.

SANTOS, Boaventura de Sousa. Sociología jurídica crítica. Para un nuevo sentido común en el derecho. Madrid: Trotta, 2009.

SANTOS, Boaventura de Sousa. "Más allá del pensamiento abisal: de las líneas globales a una ecología de los saberes". Pluralismo epistemológico. La Paz: Clacso, 2009, pp. 31-84.

TIQQUN. Introducción a la guerra civil. Ed. Melusina, 2008.

ŽIŽEK, Slavoj. Sobre la violencia. Seis reflexiones marginales. Barcelona: Paidós, 2009.

Trabalho enviado em 09 de setembro de 2019

Aceito em 06 de fevereiro de 2020 